\title{
Sulfated proteoglycans as modulators of neuronal migration and axonal decussation in the developing midbrain
}

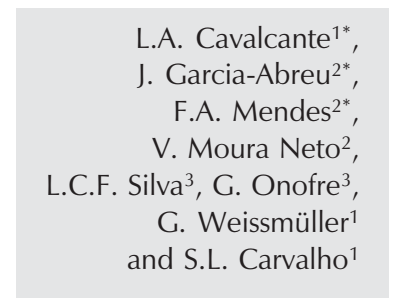

L.A. Cavalcante ${ }^{1 *}$,

Garcia-Abreu ${ }^{2 *}$,

F.A. Mendes ${ }^{2 *}$,

G. Weissmüller ${ }^{1}$

and S.L. Carvalho ${ }^{1}$

\begin{abstract}
Proteoglycans are abundant in the developing brain and there is much circumstantial evidence for their roles in directional neuronal movements such as cell body migration and axonal growth. We have developed an in vitro model of astrocyte cultures of the lateral and medial sectors of the embryonic mouse midbrain, that differ in their ability to support neuritic growth of young midbrain neurons, and we have searched for the role of interactive proteins and proteoglycans in this model. Neurite production in co-cultures reveals that, irrespective of the previous location of neurons in the midbrain, medial astrocytes exert an inhibitory or nonpermissive effect on neuritic growth that is correlated to a higher content of both heparan and chondroitin sulfates (HS and CS). Treatment of astrocytes with chondroitinase ABC revealed a growth-promoting effect of CS on lateral glia but treatment with exogenous CS-4 indicated a U-shaped dose-response curve for CS. In contrast, the growth-inhibitory action of medial astrocytes was reversed by exogenous CS-4. Treatment of astrocytes with heparitinase indicated that the growth-inhibitory action of medial astrocytes may depend heavily on HS by an as yet unknown mechanism. The results are discussed in terms of available knowledge on the binding of HS proteoglycans to interactive proteins, with emphasis on the importance of unraveling the physiological functions of glial glycoconjugates for a better understanding of neuron-glial interactions.
\end{abstract}

Research supported by FAPERJ, CNPq PRONEX, and Instituto do Milênio de Bioengenharia Tecidual.

*L.A. Cavalcante, J. Garcia-Abreu and F.A. Mendes contributed equally to this work.

Received February 18, 2003

Accepted May 21, 2003
Key words

- Astrocytes

- Axonal growth

- Chondroitin sulfate

- Heparan sulfate

- Midline

- Midbrain

\section{Introduction}

Proteoglycans are polyanionic molecules consisting of core proteins and unbranched sugar polymers, glycosaminoglycans (GAGs), which are covalently attached to specific serine residues of the protein core side chains. GAGs are linear polysaccharides of 20-200 sugars in length, built by sequential addition of identical disaccharide units onto a characteristic linkage region (1). Three types of disaccharide may be used, giving rise to 
three families of GAGs: the heparin/heparan family, the chondroitin/dermatan family, and the keratan family. The sugars of most GAGs are further modified,e.g., by $O$ - or $N$-sulfation, and GAGs are subsequently referred to as chondroitin sulfate (CS), dermatan sulfate (DS), keratan sulfate (KS), heparin, and heparan sulfate (HS). However, core proteins are not just scaffolds for GAGs but contain domains that have specific biological activities (2).

HS side chains are covalently attached to a protein core in HS proteoglycans (HSPGs) which may belong to one of three broad classes: i) those associated with the cell membrane which may have a glycosylphosphatidylinositol anchor such as the glypicans; ii) the transmembrane forms such as the syndecans; iii) those HSPGs that are secreted by cells and located in the extracellular matrix such as perlecan (2). HS chains can vary in length, epimerization of glucuronic acid to iduronic acid, overall sulfation of the chains, and position of sulfation of the monosaccharides.

Proteoglycans were originally detected in vertebrate tissues but GAGs have been identified in a wide variety of invertebrate species (for a review, see Ref. 3). The phylogenetic conservation of the physiological functions of proteoglycans has been underscored by recent work with mutants of the fruit fly Drosophila that established that proteoglycans, their associated GAGs and sulfation of heparan have a role in Wnt signaling and are required for normal development (4) . However, since HS interacts with various molecules that are essential for early morphogenesis, Drosophila mutants (and transgenic mice) that lack proper HS biosynthesis show multiple developmental defects (5). Thus, it has been difficult to study the role of HS in late developmental processes such as the main directional movements of neurons, i.e., migration of the cell body and axonal elongation.

The midbrain is a structure characterized by a remarkable dependence on the Wnt-1 (int-1) proto-oncogene, being selectively ablated in mice homozygous for null alleles of Wnt-1 (6). Closure of the neural tube at the midbrain and forebrain level is prevented by heparitinase treatment at doses that do not impair closure at more caudal levels (7). The proteoglycans and/or their glycidic moieties - GAGs - involved in neuronal migration and in axon guidance or growth have not been well characterized in vivo although they are expected to be important for several reasons including the in vitro binding to GAG chains of proteins involved in these phenomena (8).

We review here some recent studies on the effects of HS of axonal and glial proteoglycans on the specific events of neuronal migration in the midbrain and neuritic growth and guidance at choice points such as the midbrain midline and analogous sites of the central nervous system (CNS).

\section{Nervous tissue proteoglycans}

Within vertebrate tissues, there are wide variations in the extracellular matrix, with that of the mature neural tissue being considered unique by the abundance of CS proteoglycans (CSPGs) and hyaluronan (9). Most proteoglycans that are constituents of the extracellular matrix in the mature brain are hyalectans (hyaluronic and lectin-binding proteoglycans) or lecticans and carry mainly CS side chains (CSPGs) (for a review, see Ref. 10). There are also some sequence similarities in the genes encoding hyalectans and CD44, a transmembrane glycoprotein that is the main cell surface receptor for hyaluronic acid and that carries a variable number of CS side chains. CD44 has 10 or more different isoforms, with variable abilities to bind hyaluronic acid or HS (11). Other secreted proteoglycans are the keratan-containing and keratan-devoid variants of the soluble form of RPTP $\delta$ phosphatase or phosphacan and its mouse homologue DSD-1 (12). In the developing mammalian brain, aggrecan fam- 


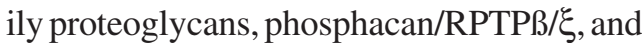
neuroglycan $\mathrm{C}$ are the major classes of CSPGs (13).

In recent years, a considerable advance has been made with respect to HSPGs represented in the neural tissue and it is known that several members of the syndecan and glypican families of HSPGs appear in neurons and glia $(10,14,15)$.

\section{Proteoglycans as part of scaffolds in the developing brain}

Cell migration is an important determinant of brain structure. In vertebrates with complex brains such as mammals, most, if not all, neurons have to migrate from the sites where they are born to places where they terminally differentiate and integrate into the brain circuitry. Radial migration of young neurons from germinal regions lining lateral ventricles to more superficial layers has been recognized as a prerequisite for proper morphogenesis and function of the cerebral cortex (16) and could be the basis for the inside-out sequence of formation of the cortex and certain cortical-like structures such as the midbrain superior colliculus (17). Tangential migration of late-born neurons has also been characterized in the cortex but it is the prototypical tangential migration that provides interneurons for the olfactory bulb (18).

A rather complex pattern of migration has been known to occur for the midbrain dopaminergic neurons destined to form the reticular formation, the substantia nigra pars compacta and the midbrain ventral tegmental area (19). Such neurons migrate in two phases, first following a ventral direction from the ventricular surface along radial processes of neuroepithelial cells and then laterally along tangentially arranged nerve fibers $(19,20)$. It is not yet clear whether migration for the midbrain tectum follows rules similar to those described for the midbrain tegmentum although the morphology of a special- ized set of radial glia, the median ventricular formation (21), suggests that selected tectal populations may follow a sequence of radial and tangential migration.

Recent work has suggested that the HSPG $\mathrm{N}$-syndecan is involved in the tangential migration of luteinizing hormone-releasing hormone neurons from the olfactory placode to the hypothalamus (22). To our knowledge, there is no indication of a role of HSPGs in the complex pattern of neuronal migration in the midbrain tegmentum. However, there is circumstantial evidence for a role of a CSPG.

Kawano and co-workers (20) first showed that the extracellular matrix protein tenascin is transiently expressed on radial processes of neuroepithelial cells coincident with the radial migration of dopaminergic neurons and that the adhesion molecule L1 was transiently expressed on tangentially arranged axons in the ventral midbrain coincident with the lateral migration of dopaminergic neurons. Interestingly, immunoreactivity for the 6B4 proteoglycan (phosphacan), but not neurocan, was present on the cell surfaces of migratory dopaminergic neurons from the time when they were ready to attach to the L1-positive tangentially oriented fibers. These results led Kawano and collaborators (20) to suggest that heterophilic interactions between phosphacan on dopaminergic neurons and L1 (23) on tangentially arranged fibers mediate the lateral migration of dopaminergic neurons. However, there was no indication whether the GAG moiety or a peptide domain of the core protein is involved in these interactions and the directional movement they promote.

\section{CSPG and HSPG modulation of neurite growth}

The notion that proteoglycans or, more precisely, CSPGs, may contribute to a barrier function for axons crossing the CNS midline can be dated to the seminal work of Snow et al. (24), detailing the developmental 
cytological changes in the cord roof plate in rat embryos, a site avoided by dorsal root ganglion axons (25), and reporting on the presence of a KS-like immunoreactivity in the roof plate. The same epitope disappears from the dorsal midline of the spinal cord at the time of formation of the dorsal commissure $(24,25)$ and is detected in the dorsal midline of the optic tectum in neonate hamsters during the growth of retinal axons (26) that must be prevented from crossing the midline. In a subsequent analysis employing nitrocellulose-coated culture dishes as a substratum for the attachment of laminin (or NCAM) and proteoglycans of interest, the behavior of the main target population - dorsal root ganglion neurons - in explant cultures was evaluated and showed a general inhibitory action of KS/CSPGs, DSPG and, in a much smaller measure, of a chondrosarcoma tumor cell CSPG devoid of KS and predominantly 4-sulfated (27). It is interesting to note that Dou and Levine (28) subsequently showed that chondroitin 4-sulfate (CS-4), CS-6 and KS inhibit neurite outgrowth from both cerebellar and dorsal root ganglion neurons on laminin-coated surfaces, whereas DS and HS had no effect on these neurons under similar conditions.

Additional work by Snow and co-workers (29) showed that soluble CSPGs (versican-like, aggrecan-like, etc.) at different concentrations inhibited neurite outgrowth from dorsal root ganglion neurons and decreased the rate of neurite elongation on a fibronectin substratum but had little or no effect on neurite initiation or outgrowth on a laminin substratum. However, not all neurite inhibitory effects of CSPGs should be attributed to CS. For instance, CS chains of CSPG-enriched fractions such as brevican and versican V2-enriched fractions from bovine myelin contribute only to a minor extent to the inhibition of neurite growth of cerebellar neurons and the major activity seems to reside in the protein cores (30).

Unilateral application of a mixture of soluble CS-4 and CS-6 to the exposed brain of stage 28 Xenopus embryos caused navigation errors of a subpopulation of forebrain axons within the tract of the postoptic commissure (TPOC) (31). Instead of crossing the ventral midline in the preexistent ventral commissure to join the contralateral TPOC, this axonal subpopulation either continued growing longitudinally into the ventral longitudinal tract or, less often, prematurely exited the ipsilateral TPOC and extended dorsally into the diencephalon or midbrain. It was not determined whether navigational errors were restricted to a subpopulation expressing a novel glycoform of the neural cell adhesion molecule, but it was clear that axon elongation was neither inhibited nor promoted. Furthermore, immunostaining revealed that native proteoglycans containing CS-4 or CS-6 were widely expressed in the Xenopus brain and neither delineated channels, pathways, or specific choice points. For this and other reasons, these investigators proposed that exogenous CS affected axon guidance by competing for a bound molecule, possibly netrin 1 , from native CSPGs.

It should also be mentioned, in passing, that axonal response to CS-4 and CS-6 might differ in some commissural systems (32). Within the developing rat anterior commissure, CS-4 was localized on the pathway of growing, neurofilament-reactive axons while the course of tightly fasciculated axons was totally devoid of CS-6 which was, however, present in the surrounding regions.

An analysis of axon routing in the embryonic mouse optic chiasm after enzymatic removal of CS from living slices showed several age-related errors. At an early stage there was crossing of the midline at aberrant positions including formation of a retinoretinal pathway, at an intermediate stage there was abolition of the transient ipsilateral projection from the central retina, and at a late stage there was marked reduction of the ipsilateral projection from the temporal retina 
(33). At any stage, there were increases in the area and complexity of growth cones both at premidline and postmidline sites. It remains to be determined how the CS moieties of proteoglycans modulate axon routing in the optic chiasm.

In view of the experimental evidence for a midline barrier to developing retinal axons at the midbrain tectum of mammals $(21,34)$, a simplified system was developed by our groups $(35,36)$ to test the behavior of embryonic midbrain neurons on astroglial substrates derived from medial and lateral sectors of the embryonic (E-14) midbrain. Furthermore, correlations were sought between the outgrowth-inhibitory (medial astrocytes) and outgrowth-promoter (lateral astrocytes) activities of these relatively immature glial cells and their content of sulfated GAGs (37) and revealed that midbrain medial astrocytes synthesize about 1.65 times more (extracellular + pericellular) CS per unit time than lateral astrocytes. A similar ratio (medial/ lateral) was also found for the entire complement of sulfated GAGs in comparisons of the whole tectal midbrain tissue of neonate hamsters (38). These investigators also demonstrated that proteoglycan cores are expressed at similar relative levels in the midline and lateral tectum including those with molecular masses similar to those of neurocan, considered to be responsible for the inhibitory activities of reactive astrocytes (39).

Attempts to determine whether the higher content of CS in midbrain medial astrocytes was responsible for their outgrowth-inhibitory properties did not confirm this hypothesis (40). Neurons growing on medial glia previously treated with chondroitinase $\mathrm{ABC}$ underwent only a very minor increase in the proportion of cells bearing neurites and in the median total length of these processes, although there was a significant increase in the length of their largest set of neurites (95th percentile). Interestingly, the effect of chondroitinase $\mathrm{ABC}$ on lateral glia was the opposite of that on medial glia, causing a non-negligible decrease in the total length of neurites grown on the treated lateral substrate (Figure 1). It should be noted that addition of chondroitinase $\mathrm{ABC}$ had no effect on the length of neurites growing on a noncellular laminin substrate, thus reinforcing the notion that effects are exerted through glial proteoglycans.

More recent work aiming to clarify the issue of the effect of CS/CSPGs on neurite length have revealed a rather complex picture. Treatment of glial cultures with xyloside, that impairs the synthesis of CSPGs and causes pronounced release of soluble CS, revealed an enormous capacity of medial glia to secrete CS (41). Both treatment with xyloside and addition of exogenous CS-4, the major chondroitin form in midbrain glia (41), showed concentration-dependent, regionally specific effects (42). Thus, treatment of lateral astrocytes with xylosides resulted in a minor increase in the length of neurites while addition to the same glial type of CS-4 resulted in a U-shaped curve with a significant decrease of neurite length at intermediate concentrations (about $2.5 \mathrm{nM}$; Figure 2) (42).

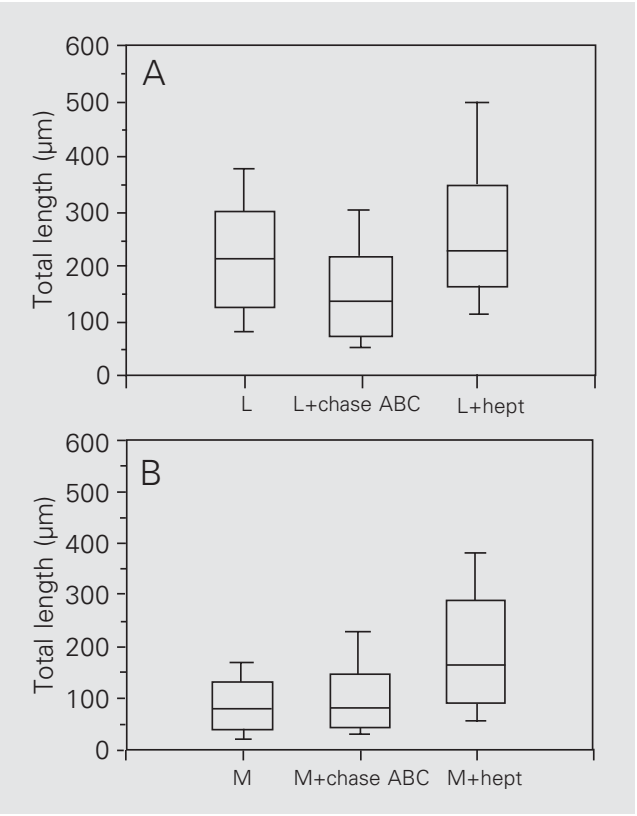

Figure 1. Effect of glycosaminoglycan lyase treatment on total length of neurites cultured on lateral (L) or medial (M) astrocytes (see also Figure 3). A, Control co-culture (L) and co-cultures treated with chondroitinase $A B C(L+$ chase $A B C)$ or heparitinase $1(\mathrm{~L}+$ hept). $B$, Control co-culture $(\mathrm{M})$ and $\mathrm{co}-$ cultures treated with chondroitinase $A B C(M+$ chase $A B C)$ or heparitinase $1(\mathrm{M}+$ hept). Boxand-whisker plots show the total length of neurites. The boxes enclose the 25th and 75th percentiles and are bisected by the median; whiskers indicate the 5th and 95th percentiles, i.e., conservative estimates for the shortest and the longest set of neurites. $L+$ chase $A B C$ and $M$ + hept are significantly different from the respective controls $L$ $(P<0.05)$ and $M(P<0.0001)$. Modified from Ref. 40, courtesy of Wiley-Liss. 
Figure 2. Effects of treatment with xyloside (methyl B-Dxylopiranoside - Xyl) or exogenous chondroitin 4-sulfate (CS4) on the relative total length of neurites (median and 95th percentile or longest set). A, Control co-culture (L) and co-cultures treated with Xyl $(\mathrm{L}+\mathrm{Xyl})$ or CS-4 (L + CS-4, 0.25, 2.5 or 25.0 nM) B, Control co-culture (M) and co-cultures treated with Xyl (M + Xyl) or CS-4 (M + CS-4, $0.25,2.5$ or $25.0 \mathrm{nM})$. Observe that $\mathrm{Xyl}$ treatment causes a striking increase of the neurite growth-promoting activity of $\mathrm{M}$ glia and a moderate increase in the same activity of $L$ astrocytes. Observe also the Ushaped dose-response curve for both the median and longest set of values of neurites after CS-4 treatment of $L$ glia. Notice also the virtual abolition of the growth-inhibitory activity of $M$ glia at CS-4 doses ranging from 0.25 to $25 \mathrm{nM}$. L, $M=$ lateral and medial astrocytes, respectively.
It is possible that both the enzymatic treatment and the addition of excess exogenous soluble CS disrupt CS-mediated binding of molecules that need not themselves be proteoglycans, with regionally specific effects as observed in the developing cortex (43). At present, there are no clues about the identity of such presumptive molecules which should be different in lateral and medial cultures. Attempts to determine differences in the complement of proteins considered to be responsible for growth-inhibitory activities of certain astrocytes such as tenascin-C (44) revealed no excess of this protein in medial astrocytes with respect to the outgrowth-promoting lateral astrocytes (40).

It has been occasionally argued that the true effects of astrocytic CSPGs could not possibly be ascertained in conventional cell cultures in which the extracellular CSPGs would not be retained on the cell surface and would be greatly diluted by the medium (39). The interpretation is that in three-dimensional cultures, as well as in the diminutive extracellular space of the mature brain, CSPGs would be trapped between the cells,

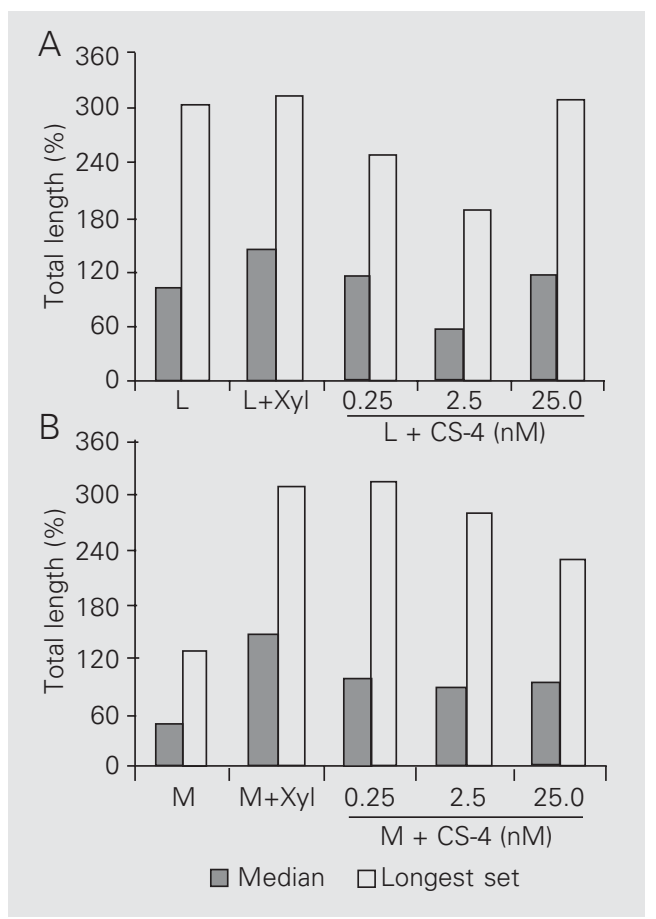

where they would be in a position to interfere with access to neurite outgrowth-promoting molecules in astrocytes.

The argument of CSPG trapping as the true environment may be applicable to the mature brain but not necessarily to the large extracellular spaces of the developing CNS tissue. Furthermore, the different effects of chondroitinase $\mathrm{ABC}$ on the growth-modulating activities of lateral and medial glia indicate a heterogeneous distribution of CSPGs themselves in our system and/or of attractive or repelling proteins to which they attach. Again, it is interesting to point out that the DSD-1 proteoglycan (the mouse homologue of phosphacan) displays opposite effects on neurite outgrowth dependent on neuronal lineage, showing a CS/DS-dependent growth-promoting effect on neurites of E-14 midbrain and E-18 hippocampal neurons and a growth-inhibitory effect on embryonic dorsal root ganglion neurons (12).

In contrast to CSPGs, little information is available in the older literature about a role of HSPGs in axon growth and guidance at the midline of the CNS. Both the older and the current literature have emphasized the idea that HSPGs play an invariant supportive role in axon growth (for a review, see Ref. 45), in spite of conflicting evidence about some HSPGs as substrates in vitro (46). This uniform viewpoint is surprising if compared to the conflicting concepts of the role played by $\mathrm{HS}$ in other events such as tumor growth and metastasis (47). As already emphasized by Turnbull and co-workers (48), there has been an increasing realization that specific sequences in the $\mathrm{HS}$ chains are designed for selective interactions with many proteins and that HS functions as a new class of multifunctional cell regulator.

Although most of the early in vitro studies reported an outgrowth-promoting activity of HSPGs (44), there were examples in which HS-binding proteins were viewed as antagonistic to neurite extension by Tobey et 
al. in 1985 (49). Ten years after that study, this dependence on the substrate was persuasively demonstrated by Dou and Levine (28) who showed that the percentage of cerebellar neurons with neurites and the length of these neurites on a substratum of L1 + HS $(10 \mu \mathrm{g} / \mathrm{ml})$ was half of the respective values for the same neurons on an L1 (only) substratum. For comparison, similar values for CS-6 were obtained only after adding this GAG at 100-fold concentration (L1 + CS-6, $1 \mathrm{mg} / \mathrm{ml}$ ).

The relevance of HS to the modulation of axon growth and guidance at the midline may be much higher than usually believed. Heparan is expressed by SSEA-1 hypothalamic neurons in the mouse and may be involved in changes in age-related fiber order in the optic chiasm and chiasm/optic tract transition (50). Furthermore, very consistent findings on the relations of HSPGs to midline crossing have been found in the exposed live brain of Xenopus embryos. Administration of exogenous heparin or perlecan-FGF-2 to the optic tract of stage 37 40 embryos caused advanced optic axons to cross the dorsal midline via the posterior commissure (51) in addition to other navigational errors of bypassing of the optic tectum, with fibers either growing around the anterior or anterior/ventral tectal margins. Heparitinase treatment and removal of axonal HS at these late stages also caused errors in axon guidance including erroneous crossing of the midline. Actual reduction of axonal growth was observed only in early embryos (stages 32-37) in which heparitinase caused a "shortening" of the optic tract that could be reversed by the addition of FGF-2 but without correction of the navigational errors (51).

In our work on the compartmental distributions of GAGs in medial and lateral midbrain glia, we observed, but did not emphasize, that sulfated HS (or, at least, its extent of sulfation) was about 1.5 higher than sulfated CS in both cultures and that sulfated
HS in medial astrocytes was 3.25-fold higher than in lateral astrocytes (37). Interestingly, the percentage of the lane's radioactivity of radioiodinated core proteins was about 4fold higher for CSPGs than HSPGs in neonatal hamster optic tectum, with the latter being apparently due to syndecan-3 and glypican-1 and to very low levels of a soluble HSPG (38).

Treatment of medial glial cultures with heparitinase before and during co-culturing caused changes in the cell surface (52) and a dramatic reversal of medial glia outgrowthinhibitory capacity (40). The proportion of midbrain neurons cultured onto heparitinasetreated medial astrocytes that produced two or more neurites rose from about $40 \%$ to more than $80 \%$ and the median value of their total length increased more than 1.5-fold. A dramatic change also occurred in their maximal total length that became more than twice
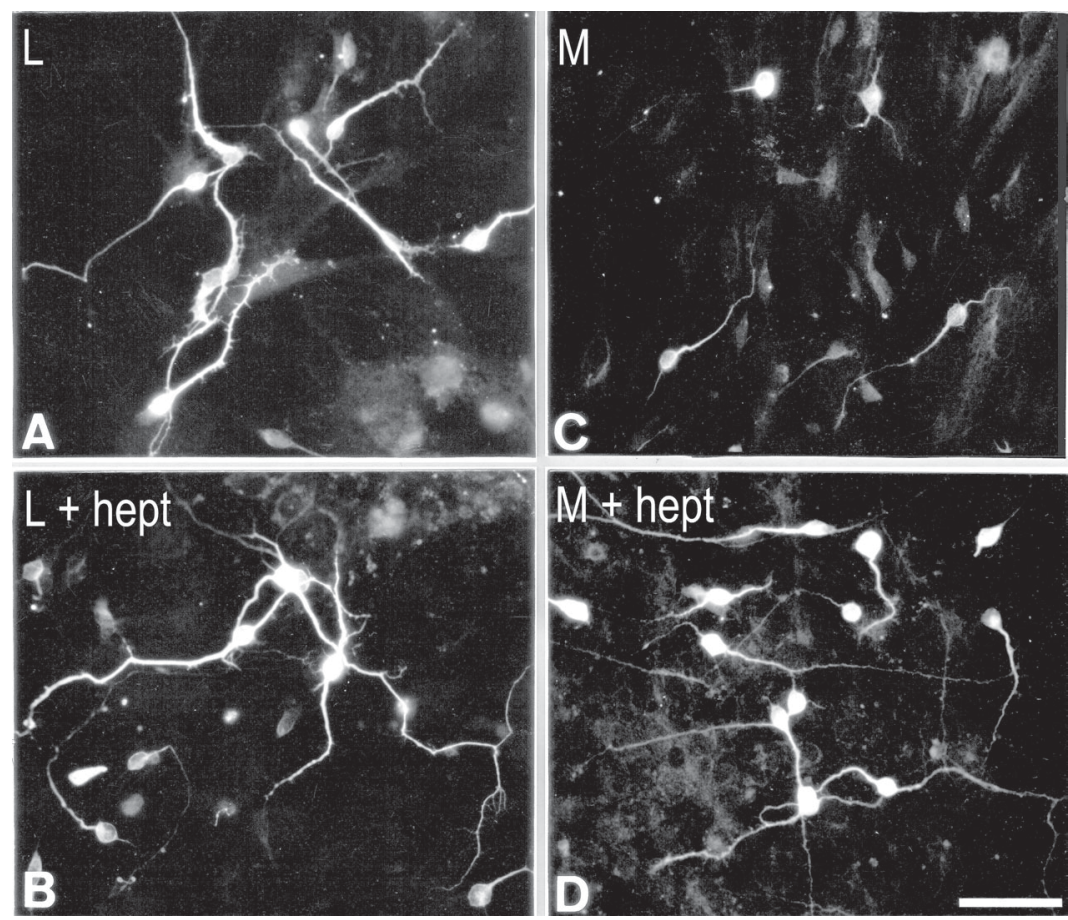

Figure 3. Photomicrographs showing predominant morphologies of MAP2-stained E-14 midbrain neurons after culturing for $24 \mathrm{~h}$ onto lateral $(\mathrm{A}, \mathrm{B})$ and medial $(\mathrm{C}, \mathrm{D})$ astrocytes. $A$ and $C$, Neurons grown onto a substrate of lateral (A) or medial astrocytes (C) without enzymatic treatment; $B$ and $D$, Neurons in co-cultures treated with heparitinase 1 (hept). Notice that hept treatment reverses the inhibitory properties of medial astrocytes (D) as also shown by $ß 3$ tubulin staining (cf. Figure 5 in Ref. 40 ). Scale bar: $50 \mu \mathrm{m}$. $\mathrm{L}=$ lateral; $M=$ medial. Reproduced from Ref. 36, courtesy of Academia Brasileira de Ciências. 
that of control neurons (Figures 1 and 3) grown on untreated medial cultures. There were also changes in co-cultures including lateral glia but they appeared to be minor in comparison to those occurring in neurons cultured onto medial glia. It is interesting to note that more recent work has shown that heparitinase treatment of striatal live sections causes them to lose their permissivity for attachment of midbrain explants in culture, whereas treatment of cortical sections attenuates their repulsive properties (53).

The main questions arising from the dramatic changes occurring in medial glia cocultures is which glial HSPG candidates are and which hypothetical mechanisms could be involved in causing inhibition of neurite growth.

At the present time, it is known that astrocytes express glypican-1 (14), which is shed from the cell surface (15) and, particularly, syndecan-2 and -4 (14), which may also be shed (54). A possible explanation for the nonpermissiveness of medial glia for neurite growth is that this cell type is the source (a) of a soluble protein with axonrepulsive activity, which is able to bind a nervous tissue HSPG (b) of (preferentially) soluble or shed HSPG. A possible candidate for the repulsive protein is the slit protein, which is expressed by midline glial specializations such as the roof and floor plates, and the chiasmatic glial palisade $(55,56)$ and, possibly, by the presumptive derivatives of the midbrain primitive midline glia (21). Slit protein is able to bind glypican-1 (8) and shows HS dependence on its collapsing activity for olfactory axons in explant cultures (57). An analogous mechanism may underlie the properties of medial astrocytes but this putative mechanism remains to be tested.

Significant new work has been done in the identification of the structural characteristics of HS that induce aberrant axon targeting such as the erroneous crossing in the Xenopus dorsal diencephalon. This bypassinducing activity has been correlated to distinct structures, particularly those containing a combination of 2-O- and 6-O-sulfate groups (58) and seems to be unrelated to $\mathrm{N}$ sulfation, which is essential for FGF-2 signaling (59). Thus, it has been hypothesized that 6- $O$-sulfated HS in the dorsal diencephalon provides a crucial component of a repulsive signal that is essential for correct axonal guidance in Xenopus. It remains to be demonstrated whether a homologous component is responsible for the contribution of HS to the nonpermissive role of the midline glia in the growth of midbrain neurites in a mammal.

\section{Acknowledgments}

We apologize to the many colleagues whose work was not cited because of space constraints.

\section{References}

1. Lander AD (1993). Proteoglycans in the nervous system. Current Opinion in Neurobiology, 3: 716-723.

2. Iozzo RV (1998). Matrix proteoglycans: From molecular design to cellular function. Annual Review of Biochemistry, 67: 609-652.

3. Nader HB, Chavante SF, dos-Santos EA et al. (1999). Heparan sulfates and heparins: similar compounds performing the same functions in vertebrates and invertebrates? Brazilian Journal of Medical and Biological Research, 32: 529-538.

4. Lin X \& Perrimon N (1999). Dally cooperates with Drosophila Frizzled 2 to transduce Wingless signalling. Nature, 400: 281-284.

5. Bullock SL, Fletcher JM, Beddington RS \& Wilson VA (1998). Renal agenesis in mice homozygous for a gene trap mutation in the gene encoding heparan sulfate 2-sulfotransferase. Genes and Develop- ment, 12: 1894-1906.

6. McMahon AP \& Bradley A (1990). The Wnt-1 (int-1) proto-oncogene is required for development of a large region of the mouse brain. Cell, 62: 1073-1085.

7. Tuckett F \& Morriss-Kay GM (1989). Heparitinase treatment of rat embryos during cranial neurulation. Anatomy and Embryology, 180: 393-400.

8. Ronca F, Andersen JS, Paech V \& Margolis RU (2001). Characterization of Slit protein interactions with glypican-1. Journal of Biological Chemistry, 276: 29141-29147.

9. Oohira A, Katoh-Semba R, Watanabe E \& Matsui F (1994). Brain development and multiple molecular species of proteoglycans. Neuroscience Research, 20: 195-207. 
10. Bandtlow CE \& Zimmermann DR (2000). Proteoglycans in the developing brain: New conceptual insights for old proteins. Physiological Reviews, 80: 1267-1290.

11. Piepkorn M, Hovingh P, Bennett KL \& Linker A (1999). Heparan sulfate composition of alternatively spliced CD44 fusion proteins. Biochemical and Biophysical Research Communications, 257: 839842.

12. Garwood J, Schnadelbach O, Clement A, Schutte K, Bach A \& Faissner A (1999). DSD-1 proteoglycan is the mouse homolog of phosphacan and displays opposing effects on neurite outgrowth dependent on neuronal lineage. Journal of Neuroscience, 19: 38883899.

13. Oohira A, Matsui F, Tokita Y, Yamauchi S \& Aono S (2000). Molecular interactions of neural chondroitin sulfate proteoglycans in the brain development. Archives of Biochemistry and Biophysics, 374: 24-34.

14. Bansal R, Kumar M, Murray K \& Pfeiffer SE (1996). Developmental and FGF-2-mediated regulation of syndecans (1-4) and glypican in oligodendrocytes. Molecular and Cellular Neurosciences, 7: 276288.

15. Winkler S, Stahl RC, Carey DJ \& Bansal R (2002). Syndecan-3 and perlecan are differentially expressed by progenitors and mature oligodendrocytes and accumulate in the extracellular matrix. Journal of Neuroscience Research, 69: 477-487.

16. Rakic P (1995). Radial glial cells: scaffolding for brain construction. In: Ketterman H \& Ransom BR (Editors), Neuroglia. Oxford University Press, New York, 746-762.

17. Cavalcante LA, Rocha-Miranda CE \& Linden R (1984). Observations on postnatal neurogenesis in the superior colliculus and the pretectum in the opossum. Developmental Brain Research, 13: 241-249.

18. Mendez-Otero R \& Cavalcante LA (1996). Expression of 9-O-acetylated gangliosides is correlated with tangential cell migration in the rat brain. Neuroscience Letters, 204: 97-100.

19. Hanaway J, McConnell JA \& Netsky MG (1971). Histogenesis of the substantia nigra, ventral tegmental area of Tsai and interpeduncular nucleus: an autoradiographic study of the mesencephalon in the rat. Journal of Comparative Neurology, 142: 59-74.

20. Kawano H, Ohyama K, Kawamura K \& Nagatsu I (1995). Migration of dopaminergic neurons in the embryonic mesencephalon of mice. Developmental Brain Research, 86: 101-113.

21. Barradas PC, Cavalcante LA, Mendez-Otero R \& Vieira AM (1989). Astroglial differentiation in the opossum superior colliculus. Glia, 2: 103-111.

22. Toba Y, Horie M, Sango K, Tokashiki A, Matsui F, Oohira A \& Kawano $H$ (2002). Expression and immunohistochemical localization of heparan sulphate proteoglycan $\mathrm{N}$-syndecan in the migratory pathway from the rat olfactory placode. European Journal of Neuroscience, 15: 1461-1473.

23. Maurel P, Rauch U, Flad M, Margolis RK \& Margolis RU (1994). Phosphacan, a chondroitin sulfate proteoglycan of brain that interacts with neurons and neural cell-adhesion molecules, is an extracellular variant of a receptor-type protein tyrosine phosphatase. Proceedings of the National Academy of Sciences, USA, 91: 25122516.

24. Snow DM, Steindler DA \& Silver J (1990). Molecular and cellular characterization of the glial roof plate of the spinal cord and optic tectum: a possible role for a proteoglycan in the development of an axon barrier. Developmental Biology, 138: 359-376.

25. Smith VL (1983). The development and postnatal organization of primary afferent projections to the rat thoracic spinal cord. Journal of Comparative Neurology, 220: 29-43.
26. Frost DO, So KF \& Schneider GE (1979). Postnatal development of retinal projections in Syrian hamsters: a study using autoradiographic and anterograde degeneration techniques. Neuroscience, 4: 16491677.

27. Snow DM, Lemmon V, Carrino DA, Caplan Al \& Silver J (1990). Sulfated proteoglycans in astroglial barriers inhibit neurite outgrowth in vitro. Experimental Neurology, 109: 111-130.

28. Dou CJ \& Levine JM (1995). Differential effects of glycosaminoglycans on neurite growth on laminin and L1 substrates. Journal of Neuroscience, 15: 8053-8066.

29. Snow DM, Brown EM \& Letourneau PC (1996). Growth cone behavior in the presence of soluble chondroitin sulfate proteoglycan (CSPG), compared to behavior on CSPG bound to laminin or fibronectin. International Journal of Developmental Neuroscience, 14 : 331-349.

30. Niederöst BP, Zimmermann DR, Schwab ME \& Bandtlow CE (1999). Bovine CNS myelin contains neurite growth-inhibitory activity associated with chondroitin sulfate proteoglycans. Journal of Neuroscience, 19: 8979-8989.

31. Anderson RB, Walz A, Holt CE \& Key B (1998). Chondroitin sulfates modulate axon guidance in embryonic Xenopus brain. Developmental Biology, 202: 235-243.

32. Fernaud-Espinosa I, Nieto-Sampedro M \& Bovolenta P (1996). Developmental distribution of glycosaminoglycans in embryonic rat brain: Relationship to axonal tract formation. Journal of Neurobiology, 30: 410-424.

33. Chung KY, Taylor JS, Shum DK \& Chan SO (2000). Axon routing at the optic chiasm after enzymatic removal of chondroitin sulfate in mouse embryos. Development, 127: 2673-2683.

34. Jhaveri S (1993). Midline glia of the tectum: a barrier for developing retinal axons. Perspectives on Developmental Neurobiology, 1: 237243.

35. Garcia-Abreu J, Moura Neto V, Carvalho SL \& Cavalcante LA (1995). Regionally specific properties of midbrain glia: I. Interactions with midbrain neurons. Journal of Neuroscience Research, 40: 471-477.

36. Cavalcante LA, Garcia-Abreu J, Moura Neto V, Silva LC \& Weissmüller G (2002). Modulators of axonal growth and guidance at the brain midline with special reference to glial heparan sulfate proteoglycans. Anais da Academia Brasileira de Ciências, 74: 691716.

37. Garcia-Abreu J, Silva LCF, Tovar FF, Onofre GR, Cavalcante LA \& Moura Neto V (1996). Compartmental distribution of sulfated glycosaminoglycans in lateral and medial midbrain astroglial cultures. Glia, 17: 339-344

38. Hoffman-Kim D, Lander AD \& Jhaveri S (1998). Patterns of chondroitin sulfate immunoreactivity in the developing tectum reflect regional differences in glycosaminoglycan biosynthesis. Journal of Neuroscience, 18: 5881-5890.

39. Asher RA, Morgenstern DA, Fidler PS, Adcock KH, Oohira A, Braistead JE, Levine JM, Margolis RU, Rogers JH \& Fawcett JW (2000). Neurocan is upregulated in injured brain and in cytokinetreated astrocytes. Journal of Neuroscience, 20: 2427-2438.

40. Garcia-Abreu J, Mendes FA, Onofre GR, Freitas MS, Silva LCF, Moura Neto V \& Cavalcante LA (2000). Contribution of heparan sulfate to the non-permissive role of the midline glia to the growth of midbrain neurites. Glia, 29: 260-272.

41. Onofre GR, Werneck CC, Mendes FA, Garcia-Abreu J, Moura Neto V, Cavalcante LA \& Silva LCF (2001). Astroglial cells derived from lateral and medial midbrain sectors differ in their synthesis and secretion of sulfated glycosaminoglycans. Brazilian Journal of Medical and Biological Research, 34: 251-258. 
42. Mendes F, Onofre C, Silva LC, Cavalcante LA \& Garcia-Abreu J (2003). Concentration-dependent actions of glial chondroitin sulfate on the neuritic growth of midbrain neurons. Developmental Brain Research, 142: 111-119.

43. Emerling DE \& Lander AD (1996). Inhibitors and promoters of thalamic neuron adhesion and outgrowth in embryonic neocortex: functional association with chondroitin sulfate. Neuron, 17: 10891100.

44. Meiners S, Powell EM \& Geller HM (1995). A distinct subset of tenascin/CS-6-PG-rich astrocytes restricts neuronal growth in vitro. Journal of Neuroscience, 15: 8096-8108.

45. Dow KE \& Wang W (1998). Cell biology of astrocyte proteoglycans. Cellular and Molecular Life Sciences, 54: 567-581.

46. Halfter W, Schurer B, Yip J, Yip L, Tsen G, Lee JA \& Cole GJ (1997). Distribution and substrate properties of agrin, a heparan sulfate proteoglycan of developing axonal pathways. Journal of Comparative Neurology, 383: 1-17.

47. Liu D, Shriver Z, Venkataraman G, El Shabrawi Y \& Sasisekharan R (2002). Tumor cell surface heparan sulfate as cryptic promoters or inhibitors of tumor growth and metastasis. Proceedings of the National Academy of Sciences, USA, 99: 568-573.

48. Turnbull J, Powell A \& Guimond S (2001). Heparan sulfate: decoding a dynamic multifunctional cell regulator. Trends in Cell Biology, 11: 75-82.

49. Tobey SL, McClelland KJ \& Culp LA (1985). Neurite extension by neuroblastoma cells on substratum-bound fibronectin's cell-binding fragment but not on the heparan sulfate-binding protein, platelet factor-4. Experimental Cell Research, 158: 395-412.

50. Chung K-Y, Leung K-M, Lin L \& Chan S-O (2001). Heparan sulfate proteoglycan expression in the optic chiasm of mouse embryos. Journal of Comparative Neurology, 436: 236-247.

51. Walz A, McFarlane S, Brickman YG, Nurcombe V, Bartlett PF \& Holt
CE (1997). Essential role of heparan sulfates in axon navigation and targeting in the developing visual system. Development, 124: 2421 2430 .

52. Weissmüller G, Garcia-Abreu J, Bisch PM, Moura Neto V \& Cavalcante LA (2000). Glial cells with differential neurite growthmodulating properties probed by atomic force microscopy. Neuroscience Research, 38: 217-220.

53. Macé K, Saxod R, Feuerstein C, Sadoul R \& Hemming FJ (2002). Chondroitin and keratan sulfates have opposing effects on attachment and outgrowth of ventral mesencephalic explants in culture. Journal of Neuroscience Research, 70: 46-56.

54. Bernfield M, Götte M, Park PW, Reizes O, Fitzgerald ML, Lincecum J \& Zako M (1999). Functions of cell surface heparan surface proteoglycans. Annual Review of Biochemistry, 68: 729-777.

55. Brose K \& Tessier-Lavigne M (2000). Slit proteins: key regulators of axon guidance, axonal branching, and cell migration. Current Opinion in Neurobiology, 10: 95-102.

56. Plump AS, Erskine E, Sabatier C, Brose K, Epstein CJ, Goodman CS, Mason CA \& Tessier-Lavigne M (2002). Slit1 and slit2 cooperate to prevent premature midline crossing of retinal axons in the mouse visual system. Neuron, 33: 219-232.

57. Hu H (2001). Cell-surface heparan sulfate is involved in the repulsive guidance activities of Slit2 protein. Nature Neuroscience, 4 695-701.

58. Irie A, Yates EA, Turnbull JE \& Holt CE (2002). Specific heparan sulfate structures involved in retinal axon targeting. Development, 129: $61-70$

59. Yamane Y, Tohno-Oka R, Yamada S, Furuya S, Shiokawa K, Hirabayashi Y, Sugino H \& Sugahara K (1998). Molecular characterization of Xenopus embryo heparan sulfate. Differential structural requirements for the specific binding to basic fibroblast growth factor and follistatin. Journal of Biological Chemistry, 273: 7375-7381. 